\title{
Developmental and Environmental Control of Dry-matter Partitioning in Peach
}

\author{
T.M. DeJong \\ Department of Pomology, University of California, One Shields Avenue, Davis, CA 95616
}

For the last several years, research in my laboratory has been focused on studying the developmental and environmental control of dry-matter partitioning in peach [Prunus persica (L.) Batsch.] trees, based on the concept that plants grow as collections of semiautonomous but interacting organs. This concept assumes that plant genotype, triggered by developmental and environmental signals, determines current organ-specific growth potentials, and that environmental conditions dictate conditional growth capacity and respiration (both growth and maintenance) requirements of each organ at any specific time. Dry-matter partitioning at any given time is then

Received for publication 6 Oct. 1998. Accepted for publication 17 Nov. 1998. The cost of publishing this paper was defrayed in part by the payment of page charges. Under postal regulations, this paper therefore must be hereby marked advertisement solely to indicate this fact. determined by the availability of resources to be partitioned, the conditional growth capacity and maintenance requirements of each organ, and the relative ability of each organ to compete for the resources. In this paper I will present a set of five guiding principles for understanding how developmental patterns of various organs influence dry-matter partitioning within the tree over time, and propose an hypothesis for how environmental conditions may influence partitioning on a diurnal basis.

Most of the concepts that are communicated in this paper have evolved from a concerted effort to study and understand the functional carbon economy of mature, bearing peach trees. This research has been focused on the development of a mechanistically based computer simulation model, PEACH, that incorporates and integrates tree and crop growth and productivity functions in response to genetic background, changes in developmental patterns and exposure to variable environments (Grossman and DeJong, 1994b). Although a long-term 
practical goal of this modeling effort is to be able to predict the tree growth and crop yield responses of commercial peach tree orchards, the primary scientific objective is to develop a conceptual framework for understanding how fruit trees function in the field environment. We chose an economic approach to modeling because tree and crop growth and development are ultimately a function of the accumulation, distribution, and use of carbohydrates and mineral resources. Thus, the model and our experimental research in the development of the model has two major components, carbon assimilation and carbon distribution.

\section{CARBON ASSIMILATION}

Although modeling of carbon assimilation in tree crops is substantially more complex than in annual row crops because of increased variation and complexities in canopy characteristics of trees, the conceptual basis for understanding canopy functioning in both types of crops is similar. Thus, in our model we chose to use the concepts and approaches developed in the annual row crop model SUCROS >86 (Simple and Universal Crop Growth Simulator, van Keulen et al., 1982; van Kraalingen and Spitters, 1986), which explicitly simulates total daily canopy photosynthesis by Gaussian integration of the instantaneous rate of leaf photosynthesis over canopy depth and diurnal light conditions (Goudriaan, 1986; Kropff et al., 1987).

The assimilation module of SUCROS $>86$ was modified to account for the discontinuous canopy within a peach orchard using empirical data on the seasonal pattern of daily light interception to adjust the effective leave area index throughout the day (DeJong and Goudriaan, 1989b). The light-saturated, instantaneous photosynthetic rate (DeJong and Doyle, 1985; DeJong et al., 1989) was adjusted for the effect of air temperature (Grossman, unpublished data), leaf age (DeJong and Doyle, 1984), and canopy depth (DeJong and Doyle, 1985).

\section{DRY-MATTER PARTITIONING}

Developing a modeling approach for carbon or dry-matter partitioning in peach trees is more complex and conceptually challenging than estimating carbon assimilation. Because trees are large, indeterminate, and vary greatly with genetic background, accumulated environmental exposure, and management practices; a simulation model cannot be developed based on empirically derived partitioning coefficients. Over the past few years there has been a developing consensus that carbohydrate partitioning in plant is primarily driven by growth and development of individual organs (Farrar, 1993; Gifford and Evans, 1981; Ho, 1988; Marcelis, 1994; Watson and Casper, 1984). Thus, we approached the problem of carbon partitioning in peach trees by beginning to characterize and quantify the developmental patterns and growth requirements of fruit and other organs of the tree with respect to differences in genotype, environment, and management. Then we developed a conceptual framework for how the growth and development patterns of individual organs interact and ultimately determine patterns of carbohydrate partitioning in trees. The following are the guiding principles that have evolved from our attempt to logically model the partitioning process.

1) A tree is a collection of semiautonomous organs and each organ has a genetically determined, organ-specific developmental pattern and growth potential.

2) The genetic growth potential of an organ is activated or deactivated by endogenous and/or environmental signals.

3) Once activated, genetic growth potential interacts with current environmental conditions (temperature, light, water status, nutrients, etc.) to determine conditional organ growth capacity.

4) Realized organ growth is a consequence of conditional organ growth capacity, total free resource availability (assimilates and nutrients), and inter-organ competition for those resources.

5) Inter-organ competition for resources is a function of location relative to the sources of carbohydrates, organ sink efficiency, and organ microenvironment.

The remainder of this paper will be devoted to discussing each of these five guiding principles and how we are attempting to functionally integrate these principles in a simulation model.
1) A tree is a collection of semiautonomous organs and each organ has a genetically determined, organ-specific developmental pattern and growth potential.

Although much emphasis is often placed on considering plants as highly integrated organisms, the concept of semi-autonomy among plant organs is not new (Harper, 1980; Sprugel et al., 1991; Watson and Casper, 1984; White, 1979). Indeed, the primary morphological features used to distinguish one plant species from another are at the organ or sub-organ level (i.e., leaf or fruit shape and size, floral characteristics, etc.), not at the whole-plant level. Furthermore, although variation exists, the developmental patterns and growth rates of individual organs under specified environmental conditions are predictable (Dale and Milthrope, 1983; DeJong and Goudriaan, 1989a; Grossman and DeJong, 1995b; Pavel and DeJong, 1993) and relatively easily modeled, even though overall plant form is highly variable, especially in trees. Although tree pruning and training can drastically alter the shape of fruit trees, they generally have virtually no effect on individual organ characteristics other than what can be explained by changes in the local microenvironment of those organs.

2) The genetic potential of an organ is activated or deactivated by endogenous and/or environmental signals.

The semiautonomous nature of individual organs is further demonstrated by the fact that individual organs on a tree can be experimentally activated by manipulating factors that stimulate growth of those organs independently from processes occurring in other organs in other parts of the tree. For instance, exposing individual buds on a branch to rest-breaking treatments will induce budbreak, while similar buds on other parts of the tree remain inactive (Chandler, 1942). Similarly, removing the apical meristem on a shoot will promote the activation and growth of lateral buds on the remaining part of the shoot, while buds on other shoots are unaffected (Harris, 1983). Although the exact mechanisms of the environmental and/or endogenous signals that activate organ growth are not fully understood, the primary site of activity is clearly at the organ or sub-organ level.

3) Once activated, current environmental conditions and genetic growth potential interact to determine conditional organ growth capacity.

Although often overlooked, ambient temperature is probably the single most important environmental factor influencing organ growth. The importance of temperature is related to the strong dependence of respiration on temperature. Since all real plant organ growth is dependent on enzyme activity, and plant respiration generally has a $Q_{10}$ of about two in the midrange of normal ambient temperatures (Amthor, 1989; Grossman and DeJong, 1994a; Pavel and DeJong, 1993), conditional growth capacity is highly dependent on temperature. That other environmental factors such as water status can also have a substantial effect on organ growth is well documented (Bradford and Hsiao, 1982). Extension growth of peach shoots has been successfully modeled by considering temperature and dynamic changes in shoot water status (Berman and DeJong, 1997a). Although fruit growth is often thought to be quite sensitive to plant water status, one should distinguish between growth in fresh vs. dry matter since the former is much more sensitive to water status than is the latter (Berman and DeJong, 1997b). Obviously, nutrient status also can play a role in influencing conditional organ growth capacity because certain nutrients are required as constituents for the growing organs. However, $\mathrm{N}$ availability can also influence developmental patterns in fruit (Saenz et al., 1997).

4) Realized organ growth is a consequence of conditional organ growth capacity, total free resource availability (assimilate and nutrients), and inter-organ competition for those resources.

Once the conditional growth capacity of an organ is determined by all of the specific genetic, endogenous, and environmental conditions, organ growth should proceed if the tree has enough resources (carbohydrates) to support that organ's growth and the growth of all other competing organs. If the tree does not have enough carbohydrate to support the conditional growth capacity of all organs, then the growth of an individual organ will be a function of its ability to compete for available assimilates with other organs. Much research in our laboratory has been focused on studying this inter-organ competition for assimilates by manipulating organ numbers and describing and quan- 
tifying the growth responses of other organs. Peach trees (and other synchronous blooming species) are well suited for these studies because fruit numbers can be manipulated early in the season with no subsequent stimulation of additional new reproductive sinks. This research has demonstrated that: 1) the conditional organ growth capacity of peach fruits can be described by relative growth rate functions (DeJong and Goudriaan, 1989a; Grossman and DeJong 1995a, 1995b; Pavel and DeJong, 1993); 2) realized growth of individual organs is substantially affected by organ numbers, presumably because of inter-organ competition (DeJong and Grossman, 1995; Grossman and DeJong, 1995b); and 3) when inter-organ competition is reduced by decreasing the number of growing organs on the tree, the realized organ growth rate reaches the conditional organ growth capacity as predicted by relative growth-rate function analysis (Grossman and DeJong, 1995b). Furthermore, there appears to be competition between vegetative and reproductive organs (Grossman and DeJong, 1998), and the competitive ability of a fruit varies with development stage (DeJong and Grossman, 1995).

5) Inter-organ competition for resources is a function of location relative to the sources of carbohydrates, organ sink efficiency and organ microenvironmental.

Once we obtained this level of understanding about the growth activities of individual organs and their importance in determining the carbohydrate partitioning patterns in plants, the remaining problems involved understanding the nature of inter-organ competition for assimilates. Before discussing inter-organ competition for resources directly, one should distinguish between apparent and actual competition and note that competition may be limited because of temporal separation in the developmental patterns of various organs. If wholetree carbon budgets are calculated at the end of the season, various types of organs may appear to be in direct competition with one another for available carbon. But when the seasonal patterns of growth of individual organs are analyzed, direct competition between different types of organs is often found to be limited by temporal separation of growth activities. For instance, one organ type may have growth concentrated at one time during the season while another organ type may grow primarily at another time. An example of this is rapid leaf and shoot expansion growth early in the growing season and rapid Stage III fruit development later in the season in the traditional peach cultivars (DeJong and Grossman, 1995; DeJong et al., 1987). However, in some cases, breeding programs involving economically driven selection pressures have served to intensify inter-organ competition, as in the selection of early-maturing peach cultivars by altering periods of peak fruit growth (DeJong et al., 1987; Grossman and DeJong, 1995a).

Periods of rapid root growth in fruit trees reportedly are generally out of phase with shoot and fruit growth (Atkinson, 1983; Cockcroft and Olsson, 1972; Head, 1967; Williamson and Coston, 1989). Although the differences in the timing of root growth are generally assumed to be consequences of competition (Williamson and Coston, 1989), the potential role of developmentally determined growth patterns is unknown.

Another possibility for a functional limitation of direct competition between potentially competing organs may be temporal separation between growth activities on a diurnal basis. Since respiration and growth are highly dependent on temperature, the pattern of relative temperature exposure of above- and below-ground organs may function to limit the competition between these two organ types. The fact that the tops of trees generally experience a much broader range of temperatures than the roots, with aboveground parts usually being warmer than roots during the day and cooler at night, could have significant effects on assimilate partitioning between these organ types. If the number of aboveground organs that a tree can support is a function of the number that can be supported at peak carbon demand (i.e., the warmest part of the day), then competition for carbon between the above- and below-ground parts of the tree would be minimized during the coolest part of the day, when activity of aboveground parts is reduced by lower temperatures while temperatures of below-ground parts remain relatively high. Although the current $\mathrm{PEACH}$ simulation model does not take into consideration the potential influence of diurnal patterns of above- and below-ground temperature on carbon partitioning, work is ongoing in this area.

Another factor that may influence competition for resources among organs is organ location relative to the source of carbohydrates. There is ample evidence that fruit on a well-lighted area of a branch or tree compete more effectively for carbon than those in shaded areas (Barritt et al., 1987; Southwick et al., 1990). However, the importance of sink location relative to sources is less well documented when comparing competition among organ types other than roots. Work with apple (Malus domestica Borkh.) and citrus (Citrus sp.) clearly indicates that root growth is substantially reduced in response to heavy cropping (Heim et al., 1979; Lenz, 1979). However, it is difficult to factor out the "sink distance from the source" effect for aboveground organs in the PEACH model because the collective demands of all canopyorgan types are pooled. Thus, a distance function cannot be considered since fruits, shoots, and small stems are located together in the overall canopy. In the current model, the distance function with respect to the trunk and roots is considered by arbitrarily assigning the roots a lesser priority for available carbohydrates. This, however, is not conceptually satisfying and more research is needed to address this issue.

Perhaps the most interesting, yet least understood, aspect of interorgan competition for assimilates is organ sink efficiency (Farrar, 1993). Although fruits are generally considered to be among the most efficient sinks on fruit trees, the mechanisms governing that efficiency are not well understood (Bustan et al., 1995). Furthermore, physiological, biochemical, or anatomical studies of sink activity are difficult to translate into partitioning schemes at the whole-plant level. To further complicate matters, the relative competitive abilities of sinks change during peach fruit development (DeJong and Grossman, 1995). Research on the factors that govern organ sink efficiency is clearly needed and may provide a key to manipulating carbon partitioning in fruit crops.

Although the carbon partitioning module of the current PEACH model is still relatively crude and involves several approximations and assumptions, the exercise of developing a sink demand-based partitioning scheme for peach trees has forced a systematic analysis of how carbon may be partitioned in trees. This analysis has resulted in a conceptual framework that should be useful for future studies of drymatter partitioning at the whole-tree as well as the organ level. Perhaps the most important concept to be learned by horticulturists who are not specifically studying partitioning is that partitioning of dry matter may be simply the outcome of organ developmental patterns and interorgan competition for resources within the plant, rather than being governed by some "centralized decision-making process" that allocates dry matter within the plant. Based on this concept, dry-matter partitioning does not direct the growth of the tree but is the result of the growth and development of the organs that make up the tree.

\section{Literature Cited}

Amthor, J.S. 1989. Respiration and crop productivity. Sprinter-Verlag. New York.

Atkinson, D. 1983. The growth, activity and distribution of the fruit tree root system. Plant Soil 71:23-35.

Barritt, G.H., C.R. Rom, K.R. Guelich, S.R. Drake, and M.A. Dilley. 1987. Canopy position and light effects on spur, leaf, and fruit characteristics of 'Delicious' apple. HortScience 22:402-405.

Berman, M.E. and T.M. DeJong. 1997a. Diurnal patterns of stem extension growth in peach (Prunus persica): Temperature and fluctuations in water status determine growth rate. Physiol. Plant. 100:361-370.

Bradford, K.J. and T.C. Hsiao. 1982. Physiological responses to moderate water stress, p. 263-324. In: O.L. Lange, P.S. Nobel, C.B. Osmund, H. Zielgler (eds.). Physiological plant ecology II. Water relations and carbon assimilation. Sprinter-Verlag, Berlin.

Bustan, A., Y. Erner, and E.E. Goldschmidt. 1995. Interactions between developing Citrus fruits and their supportive vascular system. Ann. Bot. 76:657-666.

Chandler, W.H. 1942. Deciduous orchards. Lea and Febiger, Philadelphia.

Cockcroft, B. and K.A. Olsson. 1972. Pattern of new root production in peach trees under irrigation. Austral. J. Agr. Res. 23:1021-1025.

Dale, J.E. and F.L. Milthorpe. 1983. General features of the production and growth of leaves. p. 151-178. In J.E. Dale and F.L. Milthorpe (eds.). The growth and functioning of leaves. Cambridge Univ. Press, Cambridge, U.K.

DeJong T.M., K.R. Day, and R.S. Johnson. 1989. Partitioning of leaf nitrogen 
with respect to within canopy light exposure and nitrogen availability in peach (Prunus persica). Trees 3:89-95.

DeJong, T.M. and J.F. Doyle. 1984. Leaf gas exchange and growth response of mature 'Fantasia' nectarine trees to paclobutrazol. J. Amer. Soc. Hort. Sci. 109:878-882.

DeJong, T.M. and J.F. Doyle. 1985. Seasonal relationships between leaf nitrogen content (photosynthetic capacity) and leaf canopy light exposure in peach (Prunus persica). Plant Cell Environ. 8:701-706.

DeJong T.M., J.F. Doyle, and K.R. Day. 1987. Seasonal patterns of reproductive and vegetative sink activity in early and late maturing peach (Prunus persica) cultivars. Physiol. Plant. 71:83-88.

DeJong, T.M. and J. Goudriaan. 1989a. Modeling peach fruit growth and carbohydrate requirements: Re-evaluation of the double-sigmoid growth pattern. J. Amer. Soc. Hort. Sci. 114:800-804.

DeJong T.M. and J. Goudriaan. 1989b. Modeling carbohydrate economy of peach fruit growth and crop production. Acta Hort. 254:103-108.

DeJong, T.M. and Y.L. Grossman. 1995. Quantifying sink and source limitations on dry matter partitioning to fruit growth in peach trees. Physiol. Plant. 95:437-443.

Farrar, J.F. 1993. Sink strength: What is it and how do we measure it? Plant Cell Environ. 16:1015-1046.

Gifford, R.M. and L.T. Evans. 1981. Photosynthesis, carbon partitioning, and yield. Annu. Rev. Plant Physiol. 32:485-509.

Goudriaan, J. 1986. A simple and fast numerical method for the computation of daily totals of crop photosynthesis. Agr. For. Meteorol. 38:249-254.

Grossman, Y.L. and T.M. DeJong. 1994a. Carbohydrate requirements for dark respiration by peach vegetative organs. Tree Physiol. 14:37-48.

Grossman, Y.L. and T.M. DeJong. 1994b. PEACH: A simulation model of reproductive and vegetative growth in peach trees. Tree Physiol. 14:329-345.

Grossman, Y.L. and T.M. DeJong. 1995a Maximum fruit growth potential and seasonal patterns of resource dynamics during peach growth. Ann. Bot. 75:553-560.

Grossman, Y.L. and T.M. DeJong. 1995b. Maximum fruit growth potential following resource limitation during peach growth. Ann. Bot 75:561-567.

Grossman, Y.L. and T.M. DeJong. 1998. Training and pruning system effects on vegetative growth potential, light interception and cropping efficiency in peach trees. J. Amer. Soc. Hort. Sci. 123:1058-1064.

Harper, J.L. 1980. Plant demography and ecological theory. Oikos 35:244-253. Harris, R.W. 1983. Arboriculture. Prentice-Hall. Englewood Cliffs, N.J.
Head, G.C. 1967. Effects of seasonal changes in shoot growth on the amount of unsuberized root on apple and plum trees. J. Hort. Sci. 42:169-180.

Heim, G., J.J. Landsberg, R.L. Watson, and P. Brain. 1979. Eco-physiology of apple trees: Dry matter production and partitioning by young Golden Delicious trees in France and England. J. Apple. Ecol. 16:179-194.

Ho, L.C. 1988. Metabolism and compartmentation of imported sugars in sink organs in relation to sink strength. Annu. Rev. Plant Physiol. 39:355-378.

Kropff, M.J., L. Bastiaans, and J. Goudriaan. 1987. Implications of improvements in modeling canopy photosynthesis in SUCROS (a simple and universal crop growth simulator). Neth. J. Agr. Sci. 35:192-194.

Lenz, F. 1979. Fruit effects on photosynthesis, light and dark respiration, p. 271-280. In: R. Marcelle, H. Clijsters, and M. Van Poucke (eds.). Photosynthesis and plant development. Dr. Junk, the Hague, The Netherlands.

Marcelis, L.F.M. 1994. A simulation model for dry matter partitioning in cucumber. Ann. Bot. 74:43-52.

Pavel, E.W. and T.M. DeJong. 1993. Relative growth rate and its relationship to compositional changes of non-structural carbohydrates in the mesocarp of developing peach fruits. J. Amer. Soc. Hort. Sci. 118:503-508.

Saenz, J.L., T.M. DeJong, and S.A. Weinbaum. 1997. Nitrogen stimulated increases in peach yields are associated with extended fruit development period and increased fruit sink capacity. J. Amer. Soc. Hort. Sci. 122:772-777.

Southwick, S.M., S.A. Weinbaum, T.T. Muraoka, W.R. Krueger, K.A. Shackel, and J.T. Yeager. 1990. Leaf attributes as indices of fruit quality in prune tree canopies. HortScience 25:751-754.

Sprugel, D.G., T.M. Hinkley, and W. Schaap. 1991. The theory and practice of branch autonomy. Annu. Rev. Ecol. System. 22:309-334.

van Keulen, H., F.W.T. Penning de Vries, and E.M. Drees. 1982. A summary model for crop growth. p. 87-97. In: F.W.T. Penning de Vries and H.H. van Laar (eds.). Simulation of plant growth and crop production. Centre for Agr. Publ. and Documentation (Pudoc), Wageningen, The Netherlands.

van Kraalingen, D. and C.J.T. Spitters. 1986. A simple and universal crop growth simulator: SUCROS '86 Internal Report, CABO/Dept. of Theor. Production Ecol., Wageningen, The Netherlands.

Watson, M.A. and B.B. Casper. 1984. Morphogentic constraints on patterns of carbon distribution in plants. Annu. Rev. Ecol. System. 15:233-258.

White, J. 1979. The plant as a metapopulation. Annu. Rev. Ecol. System. 10:109-145.

Williamson, J.G. and D.C. Coston. 1989. The relationship among root growth, shoot growth and fruit growth of peach. J. Amer. Soc. Hort. Sci. 114:180-183. 